\title{
Original article (short paper) \\ Different types of additional somatosensory information do not promote immediate benefits on gait in patients with Parkinson's disease and older adults
}

\author{
Ellen Lirani-Silva \\ Rodrigo Vitório \\ Universidade Estadual Paulista, Rio Claro, Brazil \\ Fabio Augusto Barbieri \\ Universidade Estadual Paulista, Bauru, Brazil \\ André Macari Baptista \\ Paulo Cezar Rocha dos Santos \\ Lilian Teresa Bucken Gobbi \\ Universidade Estadual Paulista, Rio Claro, Brazil
}

\begin{abstract}
Plantar cutaneous stimulation has been shown to improve gait in Parkinson's disease (PD), but the effects of different types of insoles have not been tested. We evaluated the immediate effect of different types of insoles on gait in PD patients and healthy older adults. Nineteen PD patients and nineteen healthy older adults performed and performed a walking task at their self-selected speed in three conditions: conventional insole, insole with a raised ridge around the foot perimeter, and insole with half-spheres. Plantar sensation was evaluated before and after the walking protocol. There were no differences between groups for plantar sensation before and after the walking task. PD patients demonstrated reduced stride length and stride velocity. There were no immediate benefits offered by the insoles on gait of either group. The increased plantar cutaneous stimulation does not promote immediate benefits on gait in PD patients and healthy older adults.
\end{abstract}

Keywords: Parkinson disease, mechanoreceptors, gait, foot orthoses

Resumo - "Diferentes tipos de informação somatossensorial adicional não promovem benefícios imediatos no andar de pacientes com doença de Parkinson e idosos sadios." A estimulação cutânea plantar beneficia o andar de pacientes com doença de Parkinson (DP), mas os efeitos de diferentes tipos de palmilhas ainda não foram testados. Nós avaliamos o efeito imediato de diferentes tipos de palmilhas no andar de pacientes com DP e idosos saudáveis. Dezenove pacientes com DP e dezenove idosos sadios andaram em três condições: palmilha convencional, palmilha com borda na parte externa da superfície do pé e palmilha com semi-esferas. A sensibilidade plantar foi avaliada antes e após o protocolo do andar. Não foram encontradas diferenças entre os grupos para sensibilidade plantar antes e após a tarefa do andar. Os pacientes apresentaram reduzida velocidade e menor comprimento da passada. Não foram verificados benefícios imediatos das palmilhas no andar para os grupos. O aumento na estimulação cutânea plantar não promoveu benefícios imediatos no andar de pacientes com DP e controles.

Palavras-chave: doença de Parkinson, mecanoceptor, marcha, órtese de pé

Resumen - "Diferentes tipos de información somatosensorial adicional no promueven beneficios inmediatos sobre la marcha en pacientes con enfermedad de Parkinson y los mayores saludables." La estimulación plantar beneficia el andar e de pacientes con enfermedad de Parkinson-(EP), pero los efectos de diferentes tipos de plantillas no fueron testados. Evaluamos el efecto inmediato de diferentes tipos de plantillas en el andar de pacientes con EP y en mayores saludables. Diecinueve pacientes con EP y diecinueve controles fueron evaluados en el andar en tres condiciones: plantilla convencional, plantilla con borde en la superficie exterior del pie e plantilla con semi-esferas. La sensibilidad plantar fue evaluada antes y después de lo andar. No hubo diferencias entre los grupos para la sensibilidad plantar antes y después de lo andar. Los pacientes mostraron velocidad reducida y menor longitud de la zancada. No hubo beneficios inmediatos de las plantillas en el andar para los grupos. El aumento en la estimulación plantar no promovió beneficios inmediatos en el andar para los grupos.

Palabras claves: enfermedad de Parkinson, mecanoceptor, marcha, ortesis de pie 


\section{Introduction}

Gait impairments are common in patients with Parkinson's disease (PD). As a consequence of progressive degeneration of the dopamine-containing neurons in the substantia nigra pars compacta, patients with PD show shortened step and stride length, reduced velocity and time in double support phase (Ferrarin et al., 2006; Lewek, Poole, Johnson, Halawa, \& Huang, 2010; Morris, Huxham, McGinley, Doss, \& Yansek, 2001; Vallabhajosula, Buckley, Tillman, \& Hass, 2013; Vitório, Pieruccini-Faria, Stella, Gobbi, \& Gobbi, 2010; Vitório et al., 2012; Yang, Lee, Cheng, Lin, \& Wang, 2008). These gait disorders severely limit patients' mobility and quality of life and increase the risk of falling (Chu, Chi, \& Chiu, 2005; Morris et al., 2001). Patients with PD also demonstrate deficits in processing and integrating sensory information (Abbruzzese \& Berardelli, 2003; Conte, Khan, Defazio, Rothwell, \& Berardelli, 2013; Patel, Jankovic, \& Hallett, 2014; Ruiz-Sanchez de Leon, \& Fernández-Guinea, 2005), which can lead to an impaired feedback of the motor output (Conte, Khan, Defazio, Rothwell, \& Berardelli, 2013; Prätorius, Kimmeskamp, \& Milani, 2003).

In order to mitigate the impairments mentioned above, the use of additional somatosensory information has been proposed. The manipulation of somatosensory information of the soles of the feet, either by increasing or decreasing plantar sensitivity, has demonstrated the key role of this receptor region in the control of posture and gait in healthy individuals (Eils et al., 2004; Nurse, Hulliger, Wakeling, Nigg, \& Stefanyshyn, 2005; Perry, Mcilroy, \& Maki, 2000). For example, decreased plantar cutaneous sensation achieved by anesthesia of the foot sole has been demonstrated to impair static and dynamic balance control (Eils et al., 2004; Nurse, Hulliger, Wakeling, Nigg, \& Stefanyshyn, 2005; Perry, Mcilroy \& Maki, 2000). However, only few studies have investigated the effects of additional somatosensory information in patients with PD. Hamanaka (2008) observed that increased plantar cutaneous stimulation trough insoles with half-spheres all around the sole improved body sway during quiet bipedal stance in patients with PD. Specially during walking task, Jenkins et al. (2009) observed that insoles with a raised ridge around the foot perimeter improved stability of patients with PD during gait cycle. Both studies support the hypothesis that increased input to the sensory system results in an improved motor output for postural control and gait in patients with $\mathrm{PD}$.

Despite the previously mentioned benefits, the effects of different types of insoles, which stimulate different areas of the sole of the foot, have never been compared. Data of this nature would help to infer which region of the sole that, when stimulated, can offer the highest benefits to patients with PD: plantar cutaneous mechanoreceptors around the borders of the foot, that provide more information about limits of stability or the entire sole that, due to greater abundance of receptors, could provide more detailed information. In addition, the insoles used by Hamanaka have never been tested during walking. Thus, the primary aim of current study was to evaluate the immediate effect of different types of insoles, adapted from Hamanaka's and Jenkin's studies, on gait in patients with PD and healthy older adults. We hypothesized that both patients with PD and older adults would improve gait while wearing the facilitatory insoles, with greater benefits associated with stimulation area offered by the insole. As the insole with half-spheres all around the sole stimulates a greater number of plantar cutaneous mechanoreceptors (Kennedy \& Inglis, 2002), we expected greater benefits from this type of insole. We also aimed to evaluate the effects of the plantar stimulation during the walking protocol on plantar sensitivity in patients with PD and healthy older adults. It was hypothesized that both patients with PD and healthy older adults would improve plantar sensitivity after the plantar stimulation.

\section{Method}

\section{Participants}

This study adhered to the guidelines of the Declaration of Helsinki, and it was approved by the Local Ethics Committee (Process \#3590/2010). Thirty-eight subjects participated in the study, including 19 people with idiopathic PD (10 men and 9 women), and 19 neurologically healthy individuals (control group). The control group was pair-matched with people with PD by gender, age, body height, and body mass.

Patients had the diagnosis of idiopathic PD confirmed by a neurologist. People with PD without other neurological diseases and classified in Stages I-III of the Hoehn and Yahr Rating Scale (H\&Y; Hoehn \& Yahr, 1967) were included and they were on regular PD medication. Inclusion criteria were: independent walker, no cognitive impairment as judged by the Mini-Mental State Examination (MMSE; Brucki, Nitrini, Caramelli, Bertolucci, \& Okamoto, 2003), no pathology involving serious loss of sensitivity of the sole of the foot (e.g., diabetes), and no other pathology that prevented the participant to perform the task successfully.

\section{Procedures}

A neuropsychiatrist performed a clinical assessment in order to determine the stage of the disease and to test patients on the Unified Parkinson's Disease Rating Scale (UPDRS; Fahn \& Elton, 1987). Both groups were tested on the MMSE.

Following the clinical assessment, the sensitivity of intensity mechanoreceptors of both feet was determined by using Semmes-Weinstein Monofilaments (North Coast Medical, Inc., San Jose, CA; Bell-Krotoski \& Tomancik, 1987). This assessment was performed while the participant was lying on a stretcher in the supine position. The leg of the foot to be evaluated was resting on a pillow in order to avoid the foot to touch the stretcher. Seven sites of plantar foot were examined: $1^{\text {st }}, 3^{\text {rd }}$ and $5^{\text {th }}$ metatarsal head and distal phalanx, and medial portion of the heel. In order to avoid the participants to view the stimulation procedure, they were blindfolded by a black elastic band. The score for each site could range from 1 to 7 and the total score for each foot was calculated by the sum of the 
scores of all sites. The minimum score was 7 and the maximum score was 49 points for each foot. The higher the total score, the greater deficits in plantar sensitivity.

Afterwards, participants performed the walking task protocol. The walking task required participants to walk, at a self-paced speed while wearing different insole types, on a pathway $8 \mathrm{~m}$ long by $1.4 \mathrm{~m}$ wide. All insoles were made of Ethylene-vinyl acetate (EVA) on the basis ( $2 \mathrm{~mm}$ high; medium density). The insole size was customized to each participant. In order to avoid the effect of insole deformation, each participant used new insoles pairs. The insoles were placed inside standard flat shoe (similar to ballet shoes) that was provided to each participant and was therefore common across all participants. Three conditions of insole type were tested (Figure 1): i) conventional insole (baseline condition): flat insole of conventional footwear; ii) insole with half-spheres: this type of insole had elevations in the form of half-spheres with a diameter of $9 \mathrm{~mm}$ in the entire area. The elevations were placed on distal phalanx of the hallux, heads of metatarsophalangeal joints and heel. These regions are the most commonly used points for the control of body sway and they contain the largest number of slow-adapting receptors (Kenedy $\&$ Inglis, 2002); iii) insole with a raised ridge around the foot perimeter, adapted from Jenkins et al. (2009). These regions are more related to information about limits of stability: this insole type had a ridge $3 \mathrm{~mm}$ high positioned at the external area of the plantar surface. Three trials in each condition per participant (9 trials) were performed in blocks. Participants performed the first block wearing the conventional insole. The presentation order of the other two blocks was randomized. Participants were blinded as to which insole they were wearing in each block. After the walking task, plantar sensibility assessment was repeated.

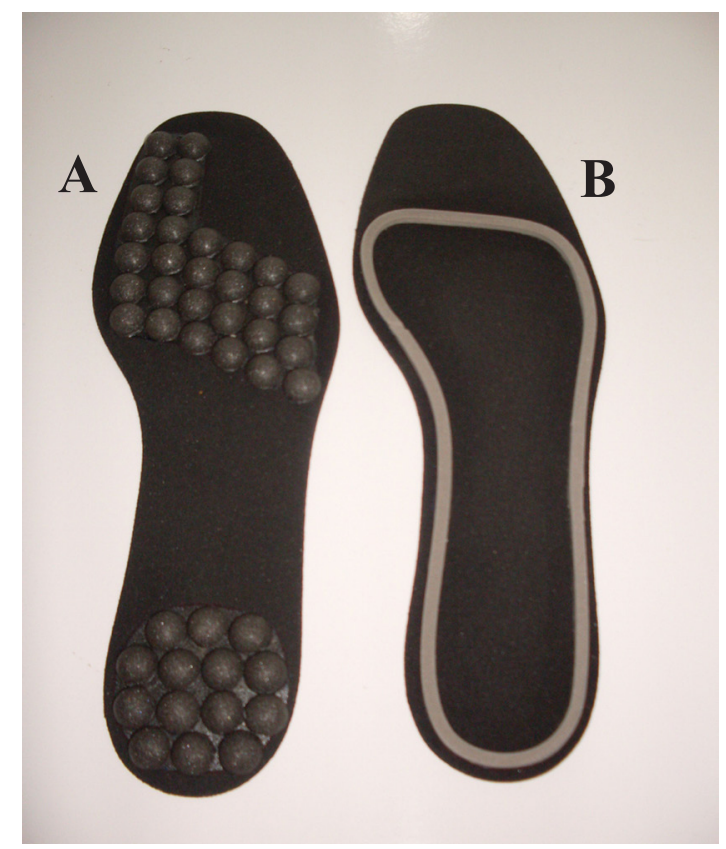

Figure 1. Insoles made for the additional somatosensory information: A - Insole with half-spheres; B - Insole with a raised ridge around the foot perimeter.

\section{Data analysis}

The kinematic data were recorded using an optoelectronic tridimensional system (OPTOTRAK Certus ${ }^{\circledR}$, Northern Digital Inc.). Four markers were attached to the following anatomic landmarks: (a) $5^{\text {th }}$ right and $1^{\text {st }}$ left metatarsal joints and (b) lateral face of the right calcaneus and medial face of the left calcaneus. The data from the central area of the pathway were recorded at a frequency of $100 \mathrm{~Hz}$. The following dependent variables were calculated on the central right stride, from heel contact to the next heel contact: stride length, stride duration, stride velocity, cadence, step width percentage of double-support phase duration, and stance phase duration.

\section{Statistical analysis}

Descriptive statistics were used to present the results. For demographic data, unrelated sample student t-tests were employed for between-group comparisons. For plantar sensitivity, two-way ANOVAs (group x moment) were carried out, with repeated measures in the moment factor (pre- and post-test). For kinematic variables, three-way ANOVAs (group $\mathrm{x}$ insole type $\mathrm{x}$ trial) were carried out, with repeated measures in the insole type and trial factors. The $p$-value was set at .05 .

\section{Results}

The two groups were not significantly different in demographic data. Mean and $\mathrm{p}$ values of $t$-tests for age, body height, body mass, and MMES are outlined in Table 1. Clinical data for the individuals with $\mathrm{PD}$ are also reported in Table 1.

Table 1. Means \pm standard deviations of the demographic data for each group and clinical data for PD patients.

\begin{tabular}{lccc}
\hline Variables & Parkinson & Control & $p$-value \\
\hline Age (years) & $71.84 \pm 7.12$ & $71.73 \pm 6.64$ & $p=.963$ \\
Body mass (kg) & $65.6 \pm 11.4$ & $72 \pm 13.07$ & $p=.117$ \\
Height (cm) & $160.62 \pm 8.75$ & $161.24 \pm 7.2$ & $p=.813$ \\
MMES (score) & $27.52 \pm 2.31$ & $28.42 \pm 2$ & $p=.201$ \\
H\&Y (stage) & $1.95 \pm 0.44$ & - & \\
UPDRS-I (score) & $3.42 \pm 2$ & - & \\
UPDRS-II (score) & $15 \pm 5.35$ & - & \\
UPDRS-III (score) & $28.1 \pm 8.7$ & - & \\
UPDRS total (score) & $46.53 \pm 13.71$ & - & \\
\hline
\end{tabular}

Note: Mini-Mental State Examination (MMSE); Hohen \& Yahr Rating Scale (H\&Y); Unified Parkinson's Disease Rating Scale: sub-scales I mentation, behavior, and mood (UPDRS-I); II - activities of daily life (UPDRS-II); III - motor evaluation (UPDRS-III) and UPDRS-total - sum of the UPDRS I, II e III. 


\section{Plantar sensitivity}

Univariate analysis did not reveal significant interaction between factors (right foot: $F_{1,20}=0.053, p=.820$; left foot: $F_{1,20}=2.490, p=.130$ ), main effect of group (right foot: $F_{1,20}=$ $0.227, p=.639$; left foot: $F_{1,20}=0.686, p=.417$ ) or main effect of moment (right foot: $F_{1,20}=0.148, p=.704$; left foot: $F_{1,20}=$ $0.036, p=.852$ ) for plantar sensitivity. Plantar sensitivity data for both groups and moments are outlined in Table 2.

\section{Walking parameters}

A significant main effect of group was demonstrated for stride length $\left(F_{1,36}=12.985, p=.001\right)$ and stride velocity $\left(F_{1,36}=7.688, p\right.$ $=.009$ ); both were smaller for people with PD. No other parameters of gait demonstrated a significant main effect of group. Univariate analysis did not reveal significant interaction between factors, main effect of insole type or main effect of trial $(p>.05)$. Kinematic variables for both groups in each condition are outlined in Table 3.

Table 2. Means \pm standard deviations of the plantar sensitivity for each group before (pre) and after (post) using different types of insole.

\begin{tabular}{lcccc}
\hline \multirow{2}{*}{ SWM (score) } & \multicolumn{2}{c}{ Parkinson } & \multicolumn{2}{c}{ Control } \\
\cline { 2 - 5 } & pre & post & pre & post \\
\hline Total Score of the Right foot & $22.54 \pm 3.9$ & $22.18 \pm 5.4$ & $21.1 \pm 7.7$ & $21 \pm 8.5$ \\
Total Score of the Left foot & $23.18 \pm 4.7$ & $21.9 \pm 5.13$ & $20 \pm 6.9$ & $21 \pm 7.04$ \\
\hline
\end{tabular}

Note: Semmes-Weinstein Monofilaments (SWM).

Table 3. Means \pm standard deviations of the kinematic variables for both groups (Parkinson and control) in each insole condition (conventional insole, insole with a raised ridge around the foot perimeter and insole with half-spheres).

\begin{tabular}{|c|c|c|c|c|c|c|}
\hline \multirow{2}{*}{ Spatiotemporal parameters } & \multicolumn{3}{|c|}{ Parkinson } & \multicolumn{3}{|c|}{ Control } \\
\hline & $\mathrm{CI}$ & IR & IH & CI & IR & IH \\
\hline Stride length (m) & $1.06 \pm 0.14$ & $1.05 \pm 0.14$ & $1.04 \pm 0.14$ & $1.23 \pm 0.17$ & $1.22 \pm 0.16$ & $1.22 \pm 0.16$ \\
\hline Stride duration (s) & $1.08 \pm 0.11$ & $1.07 \pm 0.12$ & $1.08 \pm 0.13$ & $1.06 \pm 0.13$ & $1.06 \pm 0.13$ & $1.07 \pm 0.14$ \\
\hline Velocity $(\mathrm{m} / \mathrm{s})$ & $0.99 \pm 0.18$ & $0.99 \pm 0.18$ & $0.98 \pm 0.18$ & $1.18 \pm 0.25$ & $1.18 \pm 0.23$ & $1.17 \pm 0.23$ \\
\hline Cadence (stride/min) & $56.05 \pm 5.86$ & $56.9 \pm 6.46$ & $56.36 \pm 6.73$ & $57.25 \pm 7.19$ & $57.34 \pm 6.89$ & $57.19 \pm 7.19$ \\
\hline Step width $(\mathrm{cm})$ & $12.7 \pm 4.78$ & $13.49 \pm 4.28$ & $13.79 \pm 4.4$ & $12.49 \pm 3.53$ & $13.21 \pm 4.01$ & $11.94+3.18$ \\
\hline Stance $(\%)$ & $40.61 \pm 4.53$ & $40.03 \pm 3.85$ & $39.79 \pm 4$ & $40.46 \pm 5.24$ & $40.62 \pm 4.89$ & $40.02 \pm 5.04$ \\
\hline Double support (\%) & $23.99 \pm 3.79$ & $24.05 \pm 3.67$ & $24.19 \pm 4.12$ & $22.15 \pm 5.06$ & $22.24 \pm 4.44$ & $23.08 \pm 5.20$ \\
\hline
\end{tabular}

Note: Conventional insole (CI); insole with a raised ridge around the foot perimeter (IR) and insole with half-spheres (IH).

\section{Discussion}

The current study evaluated the immediate effect of different insole types on spatial-temporal parameters of gait in patients with PD and healthy older adults. The effects of the plantar stimulation during the walking protocol on plantar sensitivity were also evaluated in both groups. Patients with PD and healthy individuals did not change locomotor behavior across insole types conditions. Also, participants of both groups did not change the performance on plantar sensitivity assessment after the walking protocol. These findings suggest that none of the insole types used in this study offered immediate benefits to gait in patients with PD and healthy older adults.

Regardless of the insole type condition, current findings corroborate with the results reported in the literature about the effects of PD on gait (Ferrarin et al., 2006; Lewek et al., 2010; Morris et al., 2001; Vitório et al., 2010; Vitório et al., 2012; Vallabhajosula et al., 2013; Yang et al., 2008). Patients with PD walked slower, with shorter strides than did their matched controls. In addition, the current study did not identify significant differences for plantar sensitivity between patients with PD and healthy older adults. Both groups had mild losses in plantar sensitivity with small reduction in protective sensitivity and difficulties in fine discrimination. Kinesthesia sensation was preserved in both groups. Thus, findings suggest that patients with PD enrolled in the current study did not have more pronounced deficits in plantar sensitivity than healthy individuals. In agreement, Hamanaka (2008) did not observe impairments on plantar sensitivity in patients with PD. On the other hand, current findings are controversial to those reported by Prätorius et al. (2003), who observed that patients with PD demonstrate greater threshold of plantar sensitivity than did the healthy older adults. This controversial could be explained by methodological differences. In our study, we performed the sensitivity of intensity mechanoreceptors test three times for the first and second monofilaments (slimmer) and only one time for the other monofilaments in each site. However, Prätorius et al. (2003) performed a total of 10 stimulus in each site.

The facilitatory insoles used in the current study did not provide immediate benefit to gait of patients with $\mathrm{PD}$. In opposition, Jenkins et al. (2009) observed that the use of a facilitatory ribbed insole (with a raised ridge located at the foot's perimeter) produced a significant increase in single-limb support time in patients with PD. Additionally, the muscle activation sequence of the tibialis anterior was normalized by the ribbed insole, at the time of initial ground contact. These changes were interpreted as an overall improvement in gait pattern and stability. Authors suggested that increased input to the sensory system results in an improved motor output of gait that may translate to better balance and postural control. However, these authors did not 
measure plantar sensitivity. Of great importance, current study did not report benefits on plantar sensitivity after the walking protocol. This may explain why the participants in the current study did not improve gait measures while wearing the facilitatory insoles. In this concern, it is also possible to suggest that the amount of sensory input offered by the facilitatory insoles and/or the stimulation time (three trials wearing each insole type) was not enough to activate mechanoreceptors in the foot sole and to promote adaptations in order to improve the somatosensory input. In order to deal with both aspects, we suggest that the effects of long-term use of facilitatory insoles on parkinsonian gait should be investigated by future studies.

The lack of improvement in sensory input can be explained by changes in processing somatosensory information due to the aging process. It is well described in the literature that older people show decreased number of receptors and irregular distribution of these receptors around the foot sole (Wells, Ward, Chua, \& Inglis, 2003). Older adults also demonstrate impaired sensorimotor integration (Matsumura $\&$ Ambrose, 2006). As a consequence, some older adults may have impaired ability to detect the touch in some areas of the foot sole (Perry, 2006). Thus, we can speculate that the amount of additional somatosensory information available for both groups was not sufficient to overcome the inefficiency of the sensory system.

\section{Conclusion}

Our results suggest that increased plantar cutaneous stimulation using different facilitatory insoles did not promote immediate benefits to gait in patients with PD and healthy older adults. Additionally, plantar stimulation during the walking protocol did not promote benefits to plantar sensitivity in patients with PD and healthy older adults.

\section{Study limitations}

A couple of limitations to current study can be identified. First, the sample consisted of older patients in early stages of PD. For this reason, they did not have pronounced peripheral sensory deficits; they demonstrated mild impairments in plantar sensitivity, which is common in older adults due to the aging process (Wells et al., 2003; Matsumura \& Ambrose, 2006). Second, it is quite possible that the short time of plantar surface stimulation by the facilitatory insoles may have been decisive for the lack of benefits. Thus, we encourage future studies to investigate the effects of long-term stimulation of plantar surface on spatial-temporal parameters of gait in patients with PD and healthy older adults.

\section{References}

Abbruzzese, G., \& Berardelli, A. (2003). Sensoriomotor integration in movement disorders. Movement Disorders, 18, 231-240.
Bell-krotoski, J., \& Tomancik, E. (1987). The repeatability of testing with Semmes-Wein/stein monofilaments. The Journal of Hand Surgery, 12, 155-161.

Brucki, S.M.D., Nitrini, R., Caramelli, P., Bertolucci, P.H.F., \& Okamoto, I.H. (2003). Suggestions for utilization of the mini-mental state examination in Brazil. Arquivos de Neuro-psiquiatria, 61, 777-781.

Chu, L.W., Chi, I., \& Chiu, A.Y.Y. (2005). Incidence and predictors of falls in the Chinese elderly. Annals Academy of Medicine Singapore, 34, 60-72.

Conte, A., Khan, N., Defazio, G., Rothwell, J.C., Berardelli, A. (2013). Pathophysiology of somatosensory abnormalities in Parkinson disease. Nature Reviews Neurology, 9, 687-697.

Eils, E., Behrens, S., Mers, O., Thorwesten, L., Völker, K., \& Rosenbauma, D. (2004). Reduced plantar sensation causes a cautious walking pattern. Gait \& Posture, 20, 54-60.

Fahn, S., \& Elton, R. Members of the UPDRS. Development Comitee. (1987). The Unified Parkinson's disease rating scale. In: S. Fahn, C.D. Marsden, D. Calne, and M. Goldstein (Eds). Recent Developments in Parkinson's Disease (2, pp 153-164). Florham Park NJ: Mcmellam Health Care Information.

Ferrarin, M., Carpinella, I., Rabuffetti, M., Calabrese, E., Mazzoleni, P., Nemni, R. (2006). Locomotor Disorders in Patients at Early Stages of Parkinson's Disease: a Quantitative Analysis. IEEE Transactions on Neural Systems and Rehabilitation Engineering, 1, 1224-1227.

Hamanaka, A.Y.Y. (2008). The effects of the additional somatosensory information on the postural control: aging and Parkinson disease. (Unpublished master's thesis), Institute of Biosciences, São Paulo State University, Rio Claro, Brazil.

Hoehn, M.M., \& Yahr, M.D. (1967). Parkinsonism: onset, progression and mortality. Neurology, 17, 573-581.

Jenkins, M.E., Almeida, Q.J., Spaulding, S.J., Van Oostveen, R.B., Holmes, J.D., Johnson, A.M., \& Perry, S.D. (2009). Plantar cutaneous sensory stimulation improves single-limb support time, and EMG activation patterns among individuals with Parkinson's disease. Parkinsonism and Related Disorders, 15, 697-702.

Kennedy, P.M., Inglis, J.T. (2002). Distribution and behavior of glabrous cutaneous receptors in the human foot sole. Journal of Physiology, 538, 995-1002.

Lewek, M.D., Poole, R., Johnson, J., Halawa, O., Huang, X. (2010). Arm swing magnitude and asymmetry during gait in the early stages of Parkinson's disease. Gait \& Posture, 31, 256-260.

Matsumura, B.A., Ambrose, A. F. (2006). Balance in the elderly. Clinics in Geriatric Medicine, 22, 395-412.

Morris, E.M., Huxham, F., McGinley, J., Dodd, K., Iansek, R. (2001). The biomechanics and motor control of gait in Parkinson disease. Clinical Biomechanics, 16, 459-470.

Nurse, M.A., Hulliger, M., Wakeling, J.M., Nigg, B.M, Stefanyshyn, D.J. (2005). Changing the texture of footwear can alter gait patterns. Journal of Electromyography and Kinesiology, 15, 496-506.

Patel, N., Jankovic, J., \& Hallett, M. (2014). Sensory aspects of movement disorders. The Lancet Neurology, 13, 100-112.

Perry, S.D., William E., Mcilroy, W.E., \& Makia, B.E. (2000). The role of plantar cutaneous mechanoreceptors in the control of compensatory stepping reactions evoked by unpredictable, multi-directional perturbation. Brain Research, 877, 401-406. 
Perry, S.D. (2006). Evaluation of age-related plantar-surface insensitivity and onset age of advanced insensitivity in older adults using vibratory and touch sensation tests. Neuroscience Letters, 392, 62-67.

Prätorius, B., Kimmeskamp, S., Milani, T.L. (2003). The sensitivity of the sole of the foot in patients with Morbus Parkinson. Neuroscience Letters, 346, 173-176.

Ruiz-Sanchez de Leon, J.M., \& Fernández-Guinea S. (2005). Visuoperceptual processing in Parkinson's disease: from the retina to the frontal cortex. Revista de Neurologia, 40, 557-562.

Vallabhajosula, S., Buckley, T.A., Tillman, M.D., Hass, C.J. (2013) Age and Parkinson's disease related kinematic alterations during multi-directional gait initiation. Gait \& Posture, 37, 280-286.

Vieregge, P., Stolze, H., Klein, C., \& Heberlein, I. (1997). Gait quantitation in Parkinson's disease - locomotor disability and correlation to clinical rating scales. Journal of Neural Transmission, 104, 337-248.

Vitório, R., Pieruccini-Faria, F., Stella, F., Gobbi, S., \& Gobbi, L. T. B. (2010). Effects of obstacle height on obstacle crossing in mild Parkinson's disease. Gait \& Posture, 31, 143-146.

Vitório, R., Lirani-Silva, E., Barbieri, F. A., Raile, V., Batistela, R. A., Stella, F.; \& Gobbi, L.T.B. (2012). The role of vision in Parkinson's disease locomotion control: Free walking task. Gait \& Posture, $35,175-179$.

Wells, C., Ward, L.M., Chua, R., \& Inglis, J.T. (2003). Regional Variation and Changes with Ageing in Vibrotactile Sensitivity in the Human Footsole. Journal of Gerontology: Biological Sciences, 58A, 680-686.

Yang, Y.R., Lee, Y.Y., Cheng, S.J., Lin, P.Y., \& Wang, R.Y. (2008). Relationships between gait and dynamic balance in early Parkinson's disease. Gait \& Posture, 27, 611-615.

\section{Authors' note}

Ellen Lirani-Silva, Rodrigo Vitório, André Macari Baptista, Paulo Cezar Rocha dos Santos and Lilian Teresa Bucken Gobbi are with the Gait and Posture Studies Laboratory (LEPLO), Department of Physical Education, Universidade Estadual Paulista, Rio Claro, Brazil.

Fabio Augusto Barbieri is with Vision and Action Laboratory (LIVIA), Department of Physical Education, Universidade Estadual Paulista, Bauru, Brazil.

\section{Corresponding author}

Ellen Lirani-Silva

Universidade Estadual Paulista - UNESP - IB - Rio Claro

Laboratório de Estudos da Postura e da Locomoção - Departamento de Educação Física

Avenida 24-A, 1515 - Bela Vista-CEP: 13.506-900- Rio Claro/São Paulo/Brasil

Phone: + 5519 3526-4365 Fax: + 5519 3534-6436

E-mail: ellen.cindy@gmail.com

\section{Acknowledgments}

The authors acknowledge all the members of the PROPARKI Group (Physical Activity Program for patients with Parkinson's disease). The authors also thank for the financial support from FAPESP (2010/03650-8), CAPES and PROEX, and Podaly for manufacturing the insoles.

Manuscript received on December 15, 2014

Manuscript accepted on June 15, 2015

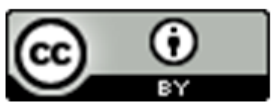

Motriz. The Journal of Physical Education. UNESP. Rio Claro, SP, Brazil - eISSN: 1980-6574 - under a license Creative Commons - Version 3.0 